\title{
Resistance to extinction as a function of percentage of reward: A reinforcement-level interpretation
}

\author{
JEFFREY A. SEYBERT, LISA P. BAER, ROBERT J. HARVEY, \\ KURT LUDWIG, and IVAN C. GERARD \\ University of Missouri-Kansas City, Kansas City, Missouri 64110
}

\begin{abstract}
Three experiments investigated the effects of percentage of reinforcement on the resistance to extinction of an instrumental running response. In Experiment 1, with N-length held constant, $47 \%$ reinforcement during acquisition generated greater resistance to extinction $\left(R_{n}\right)$ than did $77 \%$. In Experiment 2, this result was replicated with both functional N-length and number of $\mathrm{N}-\mathrm{R}$ transitions held constant. In Experiment $3, \mathrm{R}_{\mathrm{n}}$ was shown to be a function of both $\mathrm{N}$-length and percentage of reinforcement. The results of all three experiments were discussed in terms of Capaldi's reinforcement level theory and possible alternative explanations.
\end{abstract}

In general, resistance to extinction $\left(R_{n}\right)$ has been shown to increase as percentage of reward decreases (e.g., Bacon, 1962; Weinstock, 1958), although this relationship may be limited to cases of extended acquisition training (see Hall, 1976). Capaldi (1967) has explained the effects of differential percentage on the basis of differential $\mathrm{N}$-length [an $\mathrm{N}$-length is the number of consecutive nonreward $(\mathrm{N})$ trials followed by at least one rewarded $(R)$ triall. That is, in studies of differential reward percentage, schedules with smaller percentage usually contain longer $\mathrm{N}$-lengths; and since $R_{n}$ has been demonstrated to be a function of N-lengths (at least following extended training, see Capaldi, 1967), it is Capaldi's contention that results showing increased $R_{n}$ as a function of decreased percentage are confounded by increased $\mathrm{N}$-lengths. In support of this position, Capaldi (1971; see also Capaldi \& Kassover, 1970) has demonstrated that $\mathbf{R}_{\mathbf{n}}$ is a function of differential $\mathrm{N}$-length even when percentage of reward is allowed to vary. In some sense, however, this finding begs the question regarding the effects of differential percentage. While $\mathrm{N}$-length is certainly an important determinant of $R_{n}$, the findings of Capaldi (1971) and Capaldi and Kassover (1970) do not provide any direct information on the effects of variations in percentage of reward.

\section{EXPERIMENT 1}

The present experiment was designed to investigate the differences in $R_{n}$ (if any) generated by reward

This research was supported in part by a grant from the Graduate Research Council, University of Missouri-Kansas City. Requests for reprints should be sent to J. A. Seybert, Department of Psychology-C.B. Annex, University of Missouri, Kansas City, Missouri 64110. schedules containing two different percentages of partial reinforcement (PRF) $47 \%$ and $77 \%$, with $\mathrm{N}$ length held constant. Level of training was also varied so that Hall's (1976) suggestion as to the importance of this variable vis-à-vis the effects of reward percentage might be tested.

\section{Method}

Subjects. The subjects were 40 naive, male, albino SpragueDawley rats, approximately 100 days of age, purchased from the Holtzman Company.

Apparatus. The apparatus consisted of a $180 \mathrm{~cm}$ long $\times 16 \mathrm{~cm}$ high $\times 13 \mathrm{~cm}$ wide straight alley runway, constructed of $1 / 2-$ in. pine, painted with alternate vertical black/white stripes, $2.22 \mathrm{~cm}$ wide. The runway was divided into three sections, a $30-\mathrm{cm}$ start section, a $120-\mathrm{cm}$ run section, and a $30-\mathrm{cm}$ goal section. The sections were separated by guillotine doors and covered with hinged, hardwarecloth tops. The subject's progress in the alley was measured by three .01 -sec Haydon timers. The first timer, measuring the start time, was started by activation of a microswitch at the startbox door and stopped by a photocell $15 \mathrm{~cm}$ into the run section. The second timer, measuring the run time, was activated by the first photocel and stopped by a second photocell $15 \mathrm{~cm}$ in front of the goalbox. The third timer, measuring the goal time, was activated by the second photocell and stopped by a third photocell $8 \mathrm{~cm}$ inside the goalbox. Start, run, and goal speeds were obtained by converting the respective start, run, and goal latencies to reciprocals. The sum of the start, run, and goal latencies was converted to a reciprocal and served as a total speed measure. This same apparatus was also used in Experiments 2 and 3.

Procedure. Upon arrival in the laboratory, the subjects were individually housed, randomly assigned to one of four groups $(N=10$ /group), and placed on a diet of ad-lib food and water. Following 7 days of ad-lib food and water, the subjects were placed on a food-deprivation diet of $12 \mathrm{~g}$ of Purina Rat Chow per day. Food deprivation was initiated 7 days before the start of the experiment and continued throughout acquisition and extinction.

The groups varied according to level of acquisition (75 vs. 150 trials) and percentage of reinforcement $(47 \%$ vs. $77 \%)$. Thus, the four groups constituted a 2 (level of acquisition) by 2 (percentage of reinforcement) factorial design and were designated as follows: $75-47 \% ; 75-77 \% ; 150-47 \% ; 150-77 \%$. Each group received 2 days of pretraining consisting of two reinforced running trials per day. 
Reinforcement, in both pretraining and acquisition training, consisted of $1.5-\mathrm{cm}$ Startina Hog Starter (two pieces laid end-to-end, which is roughly equivalent to four $45-\mathrm{mg}$ Noyes pellets). Nonreinforcement consisted of $15-\mathrm{sec}$ confinement in the unbaited goalbox in both acquisition and extinction. Four-day repeating reward schedules were used for all groups, with the schedule being repeated 5 times for the 75-trial groups and 10 times for the 150-trial groups. The reward sequences for the $47 \%$ groups were as follows: Day 1-RNNRR; Day 2-NNR; Day 3-RNNR; Day 4-NNR. The sequences for the $77 \%$ groups were as follows: Day 1-RNNRR; Day 2-RRR; Day 3-RNNR; Day 4-RRR.

An important procedural detail should be noted here: in a daily experimental session, the $47 \%$ subjects necessarily received a smaller total amount of food, as well as a smaller percentage, than did the $77 \%$ subjects. So that any observed differences would be actually due to differential percentage rather than be confounded by differential amount of food ingested during daily trials, these differences were minimized. This was accomplished by delivering $3 \mathrm{~cm}$ ( 4 pieces) of Startina in the carrying cage following completion of the daily trials on Days 2 and 4 of the reward schedule for the $47 \%$ groups. A similar procedure was also used in Experiments 2 and 3 .

For the 150-trial groups, pretraining consisted of Days 1 and 2 of the experiment and acquisition training began on Day 3 and lasted until Day 42. The subjects in the 75-trial groups were transported to the experimental room in the carrying cage and handled on Days 1-20 (to equate all groups for handling and experience outside the home cage) received their pretraining on Days 21 and 22, and their acquisition training on Days 23-42. Thus, acquisition training terminated on the same day (Day 42) for all groups.

Following acquisition, all subjects were given 12 days of extinction at 4 trials per day, for a total of 48 extinction trials. Throughout the experiment, the subjects were run in squads of four, one from each group, with an ITI of 5-6 min.

\section{Results and Discussion}

Similar results were obtained from all sections of the alley (including the total speed measure), and, thus, only the total speed data are reported and discussed for all three experiments.

The data from the last day of acquisition were combined into a single block for purposes of analysis. The terminal speeds for the 75-47\%, 75-77\%, 150$47 \%$, and $150-77 \%$ groups were $1.18,1.16,1.26$, and $1.31 \mathrm{~m} / \mathrm{sec}$, respectively. Results of a 2 (level of training) by 2 (percentage of reward) factorial analysis of variance on these data revealed a significant level of training main effect $[F(1,36)=7.90, p<.001]$, reflecting the superiority of the 150-trial groups over the 75-trial groups. Neither the reward percentage main effect $(F<1)$ nor the Level of Training by Percentage interaction $(F<1)$ was significant, indicating no differential effect of percentage at either level of acquisition training.

So that the extinction results would not be contaminated by the terminal acquisition differences, the data from the 12 days of extinction (in blocks of four trials-days) were transformed using Anderson's (1963) rate transformation procedure. These extinction rate data are presented in Figure 1. Generally, extinction seems to have been retarded both as a function of larger amounts of training and smaller percentages of reward. That is, $R_{n}$ seems to be greater following

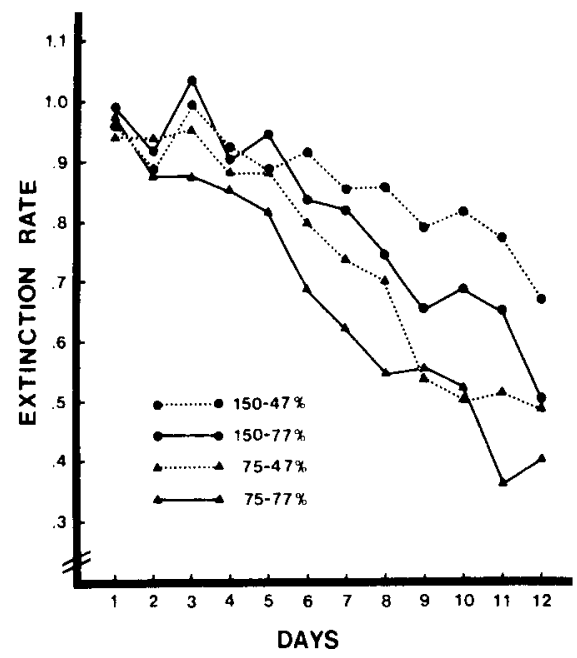

Figure 1. Mean total extinction rates for 12 days of extinction for the groups in Experiment 1.

150 trials than following 75 trials, and $47 \%$ reward seems to have generated greater $R_{n}$ than $77 \%$ reward. In addition, these differences appear in the latter part of extinction. In order to evaluate these observations, the data from the last 7 days of extinction were analyzed in a 2 (level of acquisition) by 2 (percentage of reward) by 7 (days) analysis of variance. Results of the analysis confirm the above observations; specifically, the main effects of level of training $[F(1,36)$ $=21.32, \mathrm{p}<.001]$, percentage $[\mathrm{F}(1,36)=5.56$, $\mathrm{p}<.05]$, and days $[\mathrm{F}(6,216)=20.25, \mathrm{p}<.001]$ were all significant. None of the interactions of these variables reached acceptable levels of significance.

The superiority of the 150-trial groups over the 75trial groups in the present experiment is consistent with reports of a positive relationship between $R_{n}$ and level of training in PRF situations (see Robbins, 1971), although this relationship may be limited to procedures involving a relatively small magnitude of reward (Sperling, 1965a, 1965b). The superiority of the $47 \%$ groups over the $77 \%$ groups is consistent with previous findings (e.g., Bacon, 1962; Weinstock, 1958), indicating an inverse relationship between reward percentage and $R_{n}$. Importantly, the present results indicate that this relationship holds even when $\mathrm{N}$-length is constant across the different percentage conditions. Thus, it is not necessarily the case, as suggested by Capaldi (1967), that the inverse relationship between $R_{n}$ and percentage is a procedural artifact resulting from increases in $\mathrm{N}$-length which usually accompany decreases in percentage. It is possible, of course, that previous studies confounded the percentage and $\mathbf{N}$ length variables and that observed $R_{n}$ was a function of a combination of the effects of these two variables. Nevertheless, the present results are clear in indicating that smaller percentages of reward generate greater $R_{n}$ apart from any effects of differential $N$-length, and 
also that this relationship holds across different levels of training.

It should be noted here that the $47 \%$ groups received twice as many $\mathbf{N}-\mathbf{R}$ transitions (which occur whenever an $\mathbf{R}$ trial follows an $\mathbf{N}$ trial) as did the $77 \%$ groups. It is possible that greater $R_{n}$ in the $47 \%$ vs. the $77 \%$ groups might be attributed to this factor rather than the percentage difference. Experiment 2 was performed to explore this possibility.

\section{EXPERIMENT 2}

Experiment 2 was a conceptual replication of a portion of Experiment 1. Namely, an attempt was made to replicate the effects of percentage of reward on $R_{n}$ observed in Experiment 1. Specifically, two groups received 80 acquisition trials, receiving reward on either $75 \%$ or $50 \%$ of their trials, followed by 40 nonreinforced extinction trials. In addition, both functional $N$-lengths and number of $N-R$ transitions were equated across reward percentages so that these variables would have no differential effect on $R_{n}$.

\section{Method}

Subjects. The subjects were 24 male albino rats exactly like those used in Experiment 1.

Procedure. The housing, maintenance, deprivation, and pretraining procedures in Experiment 2 were identical to those in Experiment 1 . Reinforcement and nonreinforcement were the same as in Experiment 1.

The subjects were randomly assigned to either the $75 \%$ or $50 \%$ reward groups $(\mathrm{N}=12 /$ group $)$. Two-day repeating reward schedules were used for both groups, with the schedule being repeated 10 times. The acquisition reward sequences for the $75 \%$ groups were as follows: Day 1-RNRNR; Day 2-RRR. The sequences for the $50 \%$ group were as follows: Day 1-RNRNN; Day 2-RNR.

Following acquisition, all subjects received 4 days of extinction at 10 nonreinforced trials per day, for a total of 40 extinction trials. Throughout the experiment, the subjects were run in squads of six, three subjects from each group per squad, with an ITI of 6-8 min.

\section{Results and Discussion}

The data from the last day of acquisition were combined into a single block; a t test of these data revealed that the two groups were not responding differentially at the end of training $[\mathrm{t}(22)=1.31$, $\mathrm{p}>.05]$.

So that the extinction results from Experiment 2 would be directly comparable to those from Experiment 1 , they were transformed (in two-trial blocks) using the Anderson (1963) rate transformation procedure. As can be seen in Figure 2, the two groups were not different on the 1st day of extinction, but began to diverge on Day 2, with the $50 \%$ group showing the greater $R_{n}$. On Days 3 and 4 , the $50 \%$ group showed markedly greater $R_{n}$ than did the $75 \%$ group. These observations were confirmed by the 2 (groups) by 4 (days) by 5 (trial blocks) factorial analysis of variance performed on the data.

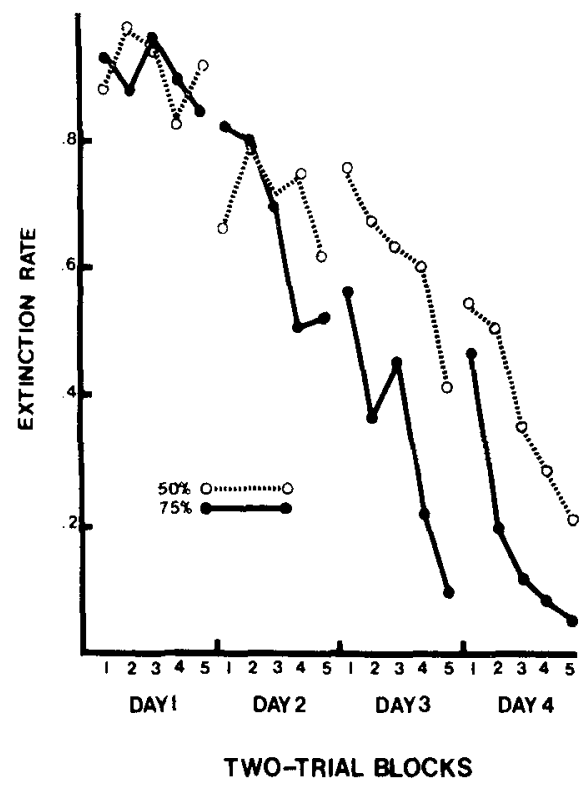

Figure 2. Mean total extinction rates (in two-trial blocks) for 4 days of extinction for the groups in Experiment 2.

The significant main effect of groups $[F(1,22)=$ $7.55, \mathrm{p}<.05$ ] reflects the overall superiority of the $50 \%$ group in extinction. Both the days main effect $[F(3,66)=89.24, p<.001]$ and the trial blocks main effect $[F(4,88)=42.35, p<.001]$ were also significant, indicating that responding in both groups declined over extinction. In addition, the interactions of Groups by Trial Blocks $[F(4,88)=5.29, p<.001]$ and Days by Trial Blocks $[\mathrm{F}(12,264)=3.80, \mathrm{p}<.001]$ were significant, while the three-way interaction was not $[F(12,264)=1.36, p>.15]$. Of major interest here, however, was the Groups by Days interaction, which was significant $[F(3,66)=4.95, p<.01]$. This interaction indicates that the groups were not different in terms of $R_{n}$ on some days of extinction (Days 1 and 2) but were different on others (Days 3 and 4), as described earlier and shown in Figure 2. Subsequent planned comparisons confirm this observation (the comparisons reported for Experiments 2 and 3 were $t$ tests conducted at the .05 level of significance), i.e., the groups were not different on Day $1(t<1)$ or on Day $2(t<1)$, but the $50 \%$ group showed greater $R_{n}$ than the $75 \%$ group on Day 3 $[\mathrm{t}(22)=3.46]$ and on Day $4[\mathrm{t}(22)=2.58]$. This development of differential $R_{n}$ within days is important to the present experiment. Note that both $\mathrm{N}$ lengths and N-R transitions were equated for the $50 \%$ and $75 \%$ groups within daily reward schedules (across 2-day blocks), and that the $50 \%$ group had both a longer N-length (two) and an extra N-R transition between days. Mackintosh and Little (1970) have shown, however, that between-day $N-R$ transitions and $\mathrm{N}$-lengths in acquisition primarily determine extinction conducted at one trial per day (spaced ex- 
tinction). $\mathrm{N}-\mathrm{R}$ transitions and $\mathrm{N}$-lengths at shorter acquisition ITIs (like those used here) primarily determine extinction conducted at massed trials (massed extinction). Since extinction in the present experiment was massed (10 trials per day) and the extinction differences were shown to occur within days, it can be concluded that these differences in $R_{n}$ were not influenced in any important way by $\mathrm{N}$-lengths and/or N-R transitions which occurred between days. Thus, the present findings replicate and extend those of Experiment 1 in showing that $R_{n}$ is inversely related to reward percentage, and that this finding obtains independently of the effects of $\mathrm{N}$-length and number of N-R transitions.

It should be noted that, in Experiments 1 and 2, the groups which received a higher percentage of reward also received CRF on alternate days, with extinction preceded by a CRF day. Thus, it is possible that the onset of extinction may have been more discriminable for these higher percentage groups. However, the discrimination hypothesis has been recently discredited (Amsel, Wong, \& Traupman, 1971; Wong, 1977). In addition, if the animals had formed such a discrimination, some indication would have been expected in terms of their acquisition performance. There was no evidence to suggest the presence of such a discrimination for animals receiving larger reward percentages.

\section{EXPERIMENT 3}

The effects of $\mathrm{N}$-length on $\mathrm{R}_{\mathrm{n}}$ are well established; as $\mathrm{N}$-length increases, $\mathbf{R}_{n}$ increases, given that a sufficient amount of acquisition training is employed (e.g., Capaldi, 1967). The importance of N-length as a major determinant of $R_{n}$ can be seen in results reported by Capaldi (1971) and Capaldi and Kassover (1970). They found that $R_{n}$ was a direct function of differential $\mathrm{N}$-length, even when percentage of reward varied as well. The results of Experiments 1 and 2 reported here, however, demonstrate that percentage of reward may also be an important determinant of $R_{n}$, particularly when $\mathbf{N}$-length is not allowed to vary. Given that both N-length and percentage of reward may determine $R_{n}$, an interesting question arises as to the effects of the combination of these two variables on $R_{n}$. Experiment 3 was designed to provide information regarding this question. Specifically, two $\mathrm{N}$-lengths (one and three) were factorially crossed with two reward percentages $(\mathbf{4 4 \%}$ and $\mathbf{7 5 \%})$ in an attempt to assess the combined effects of these two variables on $R_{n}$.

\section{Method}

Subjects. The subjects were 32 male albino rats exactly like those used in Experiment 1.

Procedure. The housing, maintenance, deprivation, and pretraining procedures in Experiment 3 were identical to those in Experiment 1. Nonreinforcement in this experiment was the same as in Experiment 1, but reinforcement consisted of $2 \mathrm{~cm}$ ( 3 pieces) of Startina Hog Starter on each R trial.

The subjects were randomly assigned to one of four groups $(\mathrm{N}=8$ /group). The four groups constituted a 2 by 2 factorial design with percentage of reinforcement $(44 \%$ vs. $75 \%)$ and $\mathrm{N}$-length (1N vs. $3 \mathrm{~N}$ ) serving as the factors. The groups were thus designated as: $1 \mathrm{~N}-44 ; 1 \mathrm{~N}-75 ; 3 \mathrm{~N}-44 ; 3 \mathrm{~N}-75$. Acquisition for all subjects consisted of six trials per day in a 6-day repeating schedule. The reward schedules for all subjects may be seen in Table 1 . The complete 6-day schedule was repeated five times for a total of 180 acquisition trials. It may be noted in Table 1 that there are several occurrences of more than one consecutive $N$ trial (for Group $1 N-44$ ) or less than three consecutive $N$ trials (for Group $3 \mathrm{~N}-44$ ) in the daily schedules. These occurrences of $\mathrm{N}$ trials are not functional $\mathrm{N}$ lengths, however, since an $\mathrm{N}$-length must be followed by at least one $R$ trial in order to effect an increase in $R_{n}$ (Capaldi, 1967). Thus, according to sequential theory, these occurrences of $N$ trials should have no effect on $\mathbf{R}_{\mathbf{n}}$.

Following acquisition, each subject received 6 extinction trials per day for 7 days, for a total of 42 extinction trials. Extinction trial procedures, the size and selection of squads, and the ITI were identical to those of Experiment 1.

\section{Results and Discussion}

An analysis of the data from the last day of acquisition (seen as point $A$ in Figure 3 ) indicated no differences between the groups.

The data from the 7 days of extinction were combined into six-trial blocks (days) for purposes of analysis and may be seen in Figure 3. Generally, longer $\mathrm{N}$-lengths and smaller percentages appear to have produced greater $R_{n}$. The data were evaluated via a 2 ( $\mathrm{N}$-length) by 2 (reward percentage) by 7 (days) factorial analysis of variance. The results revealed significant main effects for $N$-length $[F(1,28)$

Table 1

Acquisition Reward Schedules for All Groups in Experiment 3

\begin{tabular}{ccccc}
\hline & & \multicolumn{3}{c}{ Group } \\
\cline { 2 - 5 } Days & IN-44 & IN-75 & 3N-44 & 3N-75 \\
\hline $1,7,13,19,25$ & RRNRNN & RRRRNR & RRNNNR & RRNNNR \\
$2,8,14,20,26$ & NRRNRN & RNRNRR & RNNNRR & RRRRRR \\
$3,9,15,21,27$ & RNRNNN & RRNRNR & RNNNRN & RNNNRR \\
$4,10,16,22,28$ & NRNRNN & RRRRRR & RRNNNR & RRRRRR \\
$5,11,17,23,29$ & RNRRNN & RNRRNR & RNNNRN & RRNNNR \\
$6,12,18,24,30$ & NRNRNN & NRRNRR & RNNNRR & RRRRRR \\
\hline
\end{tabular}

Note $-R=$ reinforced trial, $N=$ nonreinforced trial. 


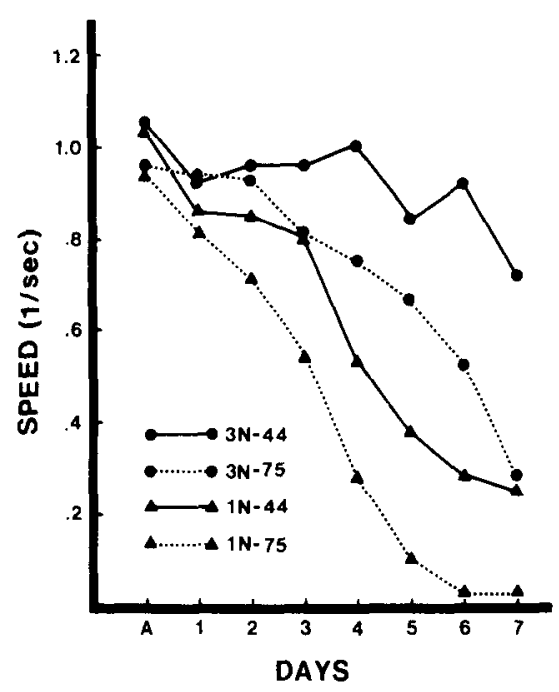

Figure 3. Mean total speeds for the last day of acquisition (A) and 7 days of extinction for the groups in Experiment 3.

$=45.08, \mathrm{p}<.001]$, reflecting the superiority of $\mathrm{N}$ lengths of three vs. $\mathrm{N}$-lengths of one; percentage $[F(1,28)=16.84, p<.001]$, reflecting the superiority of the $44 \%$ conditions vs. the $75 \%$ conditions; and days $[\mathrm{F}(6,168)=91.38, \mathrm{p}<.001]$. The significant $\mathrm{N}$ length by Percentage by Days interaction $[F(6,168)$ $=2.18, \mathrm{p}<.05]$ indicates that the differences between the groups increased over successive days of extinction. Subsequent analysis of these differences using planned comparisons indicated that $3 \mathrm{~N}-44$ was more resistant than $3 \mathrm{~N}-75[\mathrm{t}(14)=4.53], 3 \mathrm{~N}-75$ was more resistant than $1 \mathrm{~N}-44[\mathrm{t}(14)=2.09]$, and $1 \mathrm{~N}-44$ was more resistant than $1 \mathrm{~N}-75[\mathrm{t}(14)=2.19]$. In other words, the groups were ordered in terms of $R_{n}: 3 N-44>$ $3 N-75>1 N-44>1 N-75$. Thus the data from Experiment 3 reflect the effects of longer $\mathrm{N}$-lengths and smaller percentages on $R_{n}$. Capaldi and Kassover (1970) have reported an experiment conceptually similar to the present study. Essentially, they ran groups that, using our terminology, would be labeled $3 \mathrm{~N}-50,1 \mathrm{~N}-50,1 \mathrm{~N}-60$, and $1 \mathrm{~N}-75$, with the only important difference being that the $3 \mathrm{~N}-50$ group showed greater $\mathbf{R}_{\mathbf{n}}$ than the other three, which did not differ. The most troublesome finding, in view of our data, is the lack of difference between their $1 \mathrm{~N}-50$ and 1N-75 groups. There are, however, a number of possible reasons for the discrepancy between our data and those of Capaldi and Kassover. For example, their groups had different numbers of training trials (40 for the $1 \mathrm{~N}-75$ group and 60 for the $1 \mathrm{~N}-50$ group), while the groups in this experiment all had the same number of trials (180). It may be noted that, while all three experiments reported here, as well as previous findings (e.g., Bacon, 1962; Weinstock, 1958), have indicated an inverse relationship between reward percentage and $R_{n}$, other findings have also been ob- tained. Coughlin (1970) and Lewis (1952) have observed that $R_{n}$ may be a $U$-shaped function of percentage. Hall (1976), however, has attributed such findings to extremely small reward percentages and low levels of training used in those studies.

\section{GENERAL DISCUSSION}

The explanations of the effects of the sequential $\mathrm{N}$-length and $\mathrm{N}-\mathrm{R}$ transition variables are relatively straightforward and have been elaborated elsewhere, (e.g., Capaldi, 1967, 1971). The explanation of the percentage effects in the experiments reported here, however, is much less obvious. We believe that a very recent theoretical model, Capaldi's (1978) reinforcement level theory, is best equipped to handle the present percentage findings. Although the reinforcement level model, as presently constituted, was designed to deal mainly with the effects of magnitude of reward, it is our view that it can account for the effects of percentage of reward as well [in fact, Capaldi (1978) briefly discusses some effects of percentage]. This position holds that animals form expectancies in relation to the magnitude of reward that they experience. Instrumental performance is controlled, basically, as a function of the discrepancies between the animals' expectancy and what it actually receives on $R$ trials. It would seem to be a relatively simple matter to consider percentage of reward in much the same manner as is magnitude. That is, it is our contention that expectancy of reward can be influenced by reward percentage in addition to reward magnitude. According to this position, subjects receiving smaller reward percentages in acquisition would develop smaller reward expectancies than would subjects receiving larger percentages. The transition from acquisition training to extinction results in a buildup of inhibition for all subjects. However, less inhibition would accrue in extinction for subjects receiving small vs. large percentage in acquisition due to a smaller discrepancy between expected and obtained reward; and therefore, the smallpercentage subjects should show greater $\mathbf{R}_{\mathbf{n}}$ than the large-percentage subjects. These are exactly the results (in terms of the effects of percentage on $R_{n}$ ) that were observed in the experiments reported here.

The results of Experiment 3 are best explained by a combination of the sequential and reinforcement level models. It should be emphasized here that these two models are not antithetical, and, in fact, can be subsumed into a single, broader reinforcement level/ sequential theoretical model. In regard to the present findings, the sequential portion of the model accounts for the effects of $N$-length on $R_{n}$ in terms of internal cues (i.e., memories), while the reinforcement level portion of the model extends this analysis, accounting for the effects of reward percentage on $R_{n}$ by 
emphasizing the discrepancy between reward conditions in acquisition and extinction, in terms of expectancy of reward.

It should be noted that there are possible alternative explanations for the present findings. For example, frustration theory has recently been extended (e.g., Amsel et al., 1971) such that it might explain the present $\mathrm{N}$-length data (Experiment 3). Amsel et al. suggested that both short- and long-term factors influence extinction performance. The short-term factor is conceptualized to be feedback stimulus cues $\left(\mathrm{S}_{\mathrm{f}}\right)$ from primary frustration. When the ITI is relatively short (as in the present experiments), these short-term cues are assumed to be carried over and accumulated from trial to trial. Thus, at short ITIs longer $\mathrm{N}$-lengths should result in greater intensity of $S_{f}$ to which the approach response is counterconditioned, thereby generating greater $R_{n}$. This explanation, however, cannot account for differences in $R_{n}$ due to differential $N$-lengths when trials are widely spaced. Since such $\mathbf{N}$-length differences in $R_{n}$ have been observed with trials spaced at $24 \mathrm{~h}$ (Seybert, Mellgren, \& Jobe, 1973), the efficacy of the frustration explanation would seem to be seriously questioned.

Similarly, the present findings relating percentage to $\mathbf{R}_{\mathbf{n}}$ might be explained with a variety of mechanisms other than the reinforcement level approach offered above. For example, Traupmann, Amsel, and Wong (1973) demonstrated that late extinction performance was inversely related to the amount of CRF training prior to PRF training. Since, in the present studies, the larger percentage groups had days of CRF and PRF interspersed, this frustration explanation might also be applicable here. In addition, several incentive hypotheses (e.g., Ison \& Cook, 1964; Theios \& Brelsford, 1964) might account for our data. Higher incentive (which may accompany larger reward percentage) should result in greater frustration during extinction, producing less $R_{n}$.

The theoretical advantage of the explanation offered above in relation to these alternative hypotheses is, essentially, a question of parsimony. While the frustration approach might explain the present $\mathrm{N}$ length and percentage findings, it cannot, as noted above, account for very similar N-length data collected at spaced trials. Similarly, the incentive notions may explain the percentage data but cannot handle the N-length findings. On the other hand, the combined reinforcement level/sequential approach favored here can account for all the data presented and discussed herein. The important task, ultimately, is to determine which explanation can account for the most data from instrumental learning situations as a whole, rather than from a single series of experiments. In our view, at the present time, the rein- forcement level/sequential approach seems to be the most effective explanation in this regard.

\section{REFERENCES}

Amsel, A., Wong, P. T. P., \& Traupmann. K. L. Short-term and long-term factors in extinction and durable persistence Journal of Experimental Psychology, 1971, 90, 90-95.

Anderson, C. G. Comparison of different populations: Resistance to extinction and transfer. Psychological Review, 1963, 70, 162-179.

BACON, W. E. Partial reinforcement extinction following different amounts of training. Journal of Comparative and Physiological Psychology, 1962, 55, 998-1003.

Capaldi, E. J. A sequential hypothesis of instrumental learning. In K. W. Spence \& J. T. Spence (Eds.), The psychology of learning and motivation (Vol. 1). New York: Academic Press, 1967.

CAPALDI, E. J. Memory and learning: A sequential viewpoint. In W. K. Honig \& P. H. R. James (Eds.), Animal memory. New York: Academic Press, 1971.

CaPaldi, E. J. Reinforcement level: An expectancy-associative approach to relative reinforcement and nonreinforcement effects. In James Baerwaldt (Ed.), The Arlington symposium on learning, Stanford, Conn: Greylock, 1978.

CAPaldi, E. J., \& Kassover, K. Sequence, number of nonrewards, anticipation, and intertrial interval in extinction. Journal of Experimental Psychology, 1970, 84, 470-476.

Coughis, R. C. Frustration effect and resistance to extinction as a function of percentage of reinforcement. Journal of Experimental Psychology, 1970, 84, 113-119.

Hall, J. F. Classical conditioning and instrumental learning: $A$ contemporary approach. New York: Lippincott, 1976.

Ison, J. R., \& Cook, P. E. Extinction performance as function of incentive magnitude and number of acquisition trials. Psychonomic Science, 1964, 1, 245-246.

LE wIs, D. J. Partial reinforcement in the gambling situation. Journal of Experimental Psychology, 1952, 43, 447-450.

Mackintosh, N. J., \& LitTle, L. Effects of different patterns of reinforcement on performance under massed or spaced extinction. Psychonomic Science, 1970, 20, 1-2.

Robbins, D. Partial reinforcement: A selective review of the alleyway literature since 1960. Psychological Bulletin, 1971, 76, 415-431.

Seybert, J. A., Mellgren, R. L., \& Jobe, J. B. Sequential effects on resistance to extinction at widely spaced trials. Journal of Experimental Psychology, 1973, 101, 151-154.

SPERLING, S. E. Reversal learning and resistance to extinction: A review of the rat literature. Psychological Bulletin, 1965, 63, 281-287. (a)

SPERLING, S. E. Reversal learning and resistance to extinction: A supplementary report. Psychological Bulletin, 1965, 64, 310-312. (b)

Theios, J., \& Brelsford, J., JR. Overlearning-extinction effect as an incentive phenomenon. Journal of Experimental Psychology, 1964, 67, 463-467.

Traupmann, K. L., Amsel, A., \& Wong, P. T. P. Persistance early and late in extinction as a function of number of continuous reinforcements preceding partial reinforcement training. Animal Learning \& Behavior, 1973, 1, 219-222.

WeINSTOCK, S. Acquisition and extinction of a partially reinforced running response at a 24 -hour intertrial interval. Journal of Experimental Psychology, 1958, 56, 151-158.

Wong, P. T. P. A behavioral field approach to instrumental learning in the rat: $I$. Partial reinforcement effects and sex differences. Animal Learning \& Behavior, 1977, 5, 5-13.

(Received for publication May 16, 1978; revision accepted August 25, 1978.) 